\title{
A simple breathing circuit minimizing changes in alveolar ventilation during hyperpnoea
}

\author{
L.Z. Sommer*, S. Iscoe**, A. Robicsek*, J. Kruger*, J. Silverman*, J. Rucker*, \\ J. Dickstein*, G.A. Volgyesi*, J.A. Fisher*
}

A simple breathing circuit minimizing changes in alveolar ventilation during hyperpnoea. L.Z. Sommer, S. Iscoe, A. Robicsek, J. Kruger, J. Silverman, J. Rucker, J. Dickstein, G.A. Volgyesi, J.A. Fisher. CERS Journals Ltd 1998.

ABSTRACT: Many clinical and research situations require maintenance of isocapnia, which occurs when alveolar ventilation $\left(V^{\prime} \mathrm{A}\right)$ is matched to $\mathrm{CO}_{2}$ production.

A simple, passive circuit that minimizes changes in $V^{\prime}$ A during hyperpnoea was devised. It is comprised of a manifold, with two gas inlets, attached to the intake port of a nonrebreathing circuit or ventilator. The first inlet receives a flow of fresh gas $\left(\mathrm{CO}_{2}=0 \%\right)$ equal to the subject's minute ventilation $\left(V^{\prime} \mathrm{E}\right)$. During hyperpnoea, the balance of $V^{\mathrm{i}} \mathrm{E}$ is drawn (inlet 2) from a reservoir containing gas, the carbon dioxide tension $\left(\mathrm{PCO}_{2}\right)$ approximates that of mixed venous blood and therefore contributes minimally to $V^{\prime}$ A.

Nine normal subjects breathed through the circuit for 4 min at 15-31 times resting levels. End-tidal $\mathrm{PCO}_{2}\left(P\right.$ et, $\left.\mathrm{CO}_{2}\right)$ at rest, $0,1.5$ and $3.0 \mathrm{~min}$ were $($ mean $\pm \mathrm{SE}) 5.1 \pm 0.1 \mathrm{kPa}$ $(38.1 \pm 1.1 \mathrm{mmHg}), 4.9 \pm 0.1 \mathrm{kPa}(36.4 \pm 1.1 \mathrm{mmHg}), 5.0 \pm 0.2 \mathrm{kPa}(37.8 \pm 1.6 \mathrm{mmHg})$ and $5.0 \pm 0.2 \mathrm{kPa}(37.6 \pm 1.4 \mathrm{mmHg})(\mathrm{p}=\mathbf{0 . 5 3}$, analysis of variance (ANOVA)), respectively; without the circuit, $P$ et, $\mathrm{CO}_{2}$ would be expected to have decreased by at least $2.7 \mathrm{kPa}(20$ mmHg). Six anaesthetized, intubated dogs were first ventilated at control levels and then hyperventilated by stepwise increases in either respiratory frequency $(f R)$ from 10 to $24 \mathrm{~min}^{-1}$ or tidal volume $(V T)$ from 400 to $1,200 \mathrm{~mL}$. Increases in $f \mathrm{R}$ did not significantly affect arterial $\mathrm{CO}_{2}$ tension $\left(P \mathrm{a}, \mathrm{CO}_{2}\right)(\mathrm{p}=0.28$, ANOVA). Only the highest $V \mathrm{~T}$ decreased $\mathrm{Pa}_{\mathrm{a}} \mathrm{CO}_{2}$ from control $(-0.5 \pm 0.3 \mathrm{kPa}(-3.4 \pm 2.3 \mathrm{mmHg}), \mathrm{p}<0.05)$.

In conclusion, this circuit effectively minimizes changes in alveolar ventilation and therefore arterial carbon dioxide tension during hyperpnoea. Eur Respir J 1998; 12: 698-701.
*Dept of Anaesthesia, The Toronto Hospital, University of Toronto, Toronto Canada. ***Dept of Physiology, Queens University, Kingston, Canada.

Correspondence: J.A. Fisher

Dept of Anaesthesia

The Toronto Hospital

200 Elizabeth Street

Toronto

Canada MSG 2C4

Fax: 4163403698

Keywords: Alveolar ventilation

$\operatorname{dog}$

human

hyperpnoea

isocapnia

Received: April 291997

Accepted after revision April 71998

This study was funded in part by the Toronto Hospital-Mount Sinai Hospital Dept of Anaesthesia research Fund and the Fisher Family Foundation
Several clinical conditions [1-3] and research protocols [4-7] require increases in minute ventilation $\left(V^{\prime} \mathrm{E}\right)$ at constant (or nearly constant) arterial carbon dioxide tension $\left(P \mathrm{a}, \mathrm{CO}_{2}\right)$. At a constant $\mathrm{CO}_{2}$ production, $\mathrm{Pa}, \mathrm{CO}_{2}$ is inversely related to alveolar ventilation $\left(V^{\prime} \mathrm{A}\right)$, which is a function of $V^{\prime}$ 'E. When $V^{\prime} \mathrm{E}$ increases, $P \mathrm{a}, \mathrm{CO}_{2}$ falls unless $\mathrm{CO}_{2}$ is added to the inspired gas. Maintaining a constant $\mathrm{Pa}_{\mathrm{a}} \mathrm{CO}_{2}$ despite an irregular breathing pattern requires continuous and proportional adjustment of the fractional concentration of inspired $\mathrm{CO}_{2}\left(\mathrm{FI}, \mathrm{CO}_{2}\right)$. Manual adjustments of $F \mathrm{I}, \mathrm{CO}_{2}$ may be adequate if changes in $V^{\prime} \mathrm{E}$ are slow or if wide variations in $V^{\prime} \mathrm{A}$ are acceptable. Automated feedback systems provide finer control of $V^{\prime}$ A but can result in phase delays, unstable responses or overdamping, despite the use of expensive equipment and complex algorithms. A simple breathing circuit was developed and tested that minimizes the effect of $V^{\prime} \mathrm{E}$ on $V^{\prime}$ A by passively and continuously matching the inspired $\mathrm{CO}_{2}$ to $V^{\prime} \mathrm{E}$ regardless of the extent or pattern of breathing.

\section{Methods}

The basic concept underlying this approach is that the flow of fresh gas $\left(F \mathrm{I}, \mathrm{CO}_{2}=0\right)$ contributing to alveolar $\mathrm{CO}_{2}$ exchange is kept constant. When $V^{\prime} \mathrm{E}$ is less than or equal to the fresh gas flow (FGF), the subject inhales only fresh gas. Therefore:

$$
V^{\prime} \mathrm{A}=\mathrm{FGF}
$$

When $V^{\prime} E$ exceeds FGF, the balance of inhaled gas is drawn from a reservoir containing a reserve gas with a carbon dioxide tension $\left(\mathrm{PCO}_{2}\right)$ equal to that of mixed venous blood and thus does not participate in $\mathrm{CO}_{2}$ exchange, ensuring that $V^{\prime} \mathrm{A}$ is limited by FGF, as indicated by the following equation:

$$
\begin{gathered}
V^{\prime} \mathrm{A}=\mathrm{FGF}+\left(V^{\prime} \mathrm{E}-\mathrm{FGF}\right) \times \\
\left(\left(P \mathrm{v}_{\mathrm{v}} \mathrm{CO}_{2}-\text { reserve gas } P \mathrm{CO}_{2}\right) / P_{\mathrm{v}}, \mathrm{CO}_{2}\right)
\end{gathered}
$$

where $P \mathrm{v}, \mathrm{CO}_{2}$ is the oxygenated mixed venous $P_{\mathrm{CO}_{2}}$. When the $\mathrm{PCO}_{2}$ of the mixed venous and reserve gas are not equal, the $V^{\prime}$ A depends on both this difference and the difference between $V^{\prime} \mathrm{E}$ and FGF.

\section{Circuit description}

The circuit (fig. 1) consists of a nonrebreathing valve connected distally to two ports. The first port is connected 


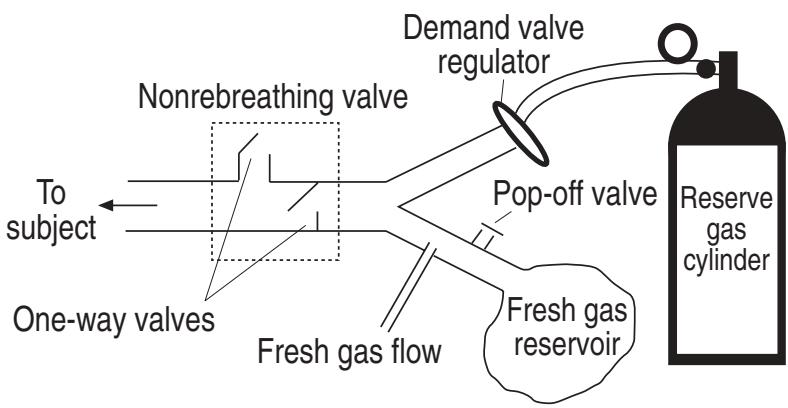

Fig. 1. - Schematic diagram of breathing circuit used for human subjects, For studies in dogs, the demand regulator was replaced with a positive end-expiratory pressure valve and the reserve gas cylinder was replaced by a Douglas bag prefilled with different concentrations of $\mathrm{CO}_{2}$.

to a source of fresh gas, a small $(<1 \mathrm{~L})$ reservoir (to collect fresh gas during exhalation) and a one-way pop-off valve (to allow venting of excess fresh gas). For the studies in human subjects, the second port was connected via an adjustable demand valve (Scubapro 150; Scubapro, Sturtevant, WI, USA) to a cylinder of reserve gas containing $5.5 \% \mathrm{CO}_{2}$. The demand valve was adjusted to an opening pressure of $\sim 1.5 \mathrm{cmH}_{2} \mathrm{O}$. For the studies in dogs, the second port was connected to a $300 \mathrm{~L}$ Douglas bag containing reserve gas with different concentrations of $\mathrm{CO}_{2}$ (see below).

\section{Human subjects}

After obtaining approval from the institutional ethics board and informed consent from the subjects, nine healthy subjects aged 19-25 yrs and ranging in weight from 55-95 kg breathed through the circuit by means of a mouthpiece and a low-resistance heat-moisture exchanger while wearing noseclips. During normal breathing, the FGF was set equal to $V^{\prime} E$ by adjusting the flowmeter until the fresh gas reservoir just emptied at the end of each inspiration. Subjects were then instructed to breathe maximally ("breathe as hard as you can") for $3 \mathrm{~min}$. Flows were recorded by means of a Pitot tube (Voltek Enterprises, Willowdale, Canada) and the signal was integrated to obtain volume. $\mathrm{CO}_{2}$ was sampled continuously at the mouthpiece (Medical Gas Analyzer LB-2; Sensormedics Corp., Anaheim, CA, USA). Analogue signals were digitized at a rate of 60 samples $\cdot \mathrm{s}^{-1}$ and recorded using data-acquisition software (WINDAQ/200, DATAQ Instruments, Akron, OH, USA).

\section{Studies in dogs}

Following approval from the institutional ethics board, six mongrel dogs of either sex weighing 20-25 kg were anaesthetized with methohexital $\left(5-7 \mathrm{mg} \cdot \mathrm{kg}^{-1}\right.$ for induction followed by an infusion of $0.15-0.30 \mathrm{mg} \cdot \mathrm{kg}^{-1} \cdot \mathrm{min}^{-1}$ ) and intubated. Adequacy of anaesthetic depth was deduced from the eyelash reflex, lack of spontaneous movements and stable cardiac frequency and blood pressure. A catheter was placed in the femoral artery for monitoring blood pressure and periodic sampling of blood for gas analysis.
The dogs were ventilated with a conventional piston ventilator (Harvard Apparatus model 618, South Natick, MA, USA). For each dog, tidal volume $(V \mathrm{~T})$ of $400 \mathrm{~mL}$ and a respiratory frequency $(f \mathrm{R})$ of $10 \mathrm{~min}^{-1}$ (duty cycle 0.5 ) were used. All dogs were ventilated to just below their apnoeic thresholds (by adjusting $V \mathrm{~T}$ by $50 \mathrm{~mL}$ increments) so that they made no respiratory efforts. Tidal $\mathrm{CO}_{2}$ was sampled continuously (Ametek, Thermox Instruments Division, Pittsburgh, PA, USA) at the proximal end of the endotracheal tube. Flow was measured with a pneumotachograph (Vertek series 47303A; Hewlett-Packard, Palo Alto, CA, USA) and the signal integrated to obtain volume. Analogue signals were digitized at a rate of 17 samples $\cdot \mathrm{s}^{-1}$ and recorded using the same data-acquisition software as that used in studies on human subjects.

Because of differences in initial $P \mathrm{a}, \mathrm{CO}_{2}$ among dogs (reflecting individual $V \mathrm{~T} /$ body weight ratios and/or anaesthetic levels), the $\mathrm{CO}_{2}$ concentration in the reserve gas was arbitrarily adjusted for each dog to approximate the $P_{\mathrm{v}, \mathrm{CO}_{2}}$. To facilitate setting the concentration of $\mathrm{CO}_{2}$ in the reserve gas for each dog, the demand valve was replaced with a one-way positive end-expiratory pressure (PEEP) valve and the cylinder with a bag containing premixed gas. This circuit is functionally identical to that used in studies on humans. The circuit was connected to the intake port of the ventilator. Under control conditions, FGF was adjusted so that the fresh gas reservoir just emptied during each ventilator cycle; this was confirmed by a slight rise in $\mathrm{F}, \mathrm{CO}_{2}$ above zero.

After attaining a steady state (difference $<0.2 \mathrm{kPa}(1.5$ $\mathrm{mmHg}$ ) in two successive $P \mathrm{a}, \mathrm{CO}_{2}$ taken 5 min apart), $V \mathrm{~T}$ was increased at $5 \mathrm{~min}$ intervals from 400 to 600 to 900 to $1,200 \mathrm{~mL}$. In a second trial at a fixed $V \mathrm{~T}$ (approximately $400 \mathrm{~mL}), \mathrm{fR}$ was increased at $5 \mathrm{~min}$ intervals from 10 to 14 to 18 to $22 \mathrm{~min}^{-1}$. An arterial blood sample for the determination of blood gases was drawn at the beginning and end of each interval.

Tests for significant differences were performed using one- or two-way analysis of variance (ANOVA) with post hoc analysis where appropriate. A p-value $<0.05$ was considered significant.

\section{Results}

\section{Human subjects}

There was considerable variability in $V^{\prime} \mathrm{E}$ and breathing patterns between subjects but individual subjects tended to sustain a particular breathing pattern throughout the run. When $V^{\prime}$ E was high in relation to FGF, both were inhaled simultaneously and subjects did not perceive any transition from fresh to reserve gas. Figure 2 presents the end tidal $\mathrm{PCO}_{2}\left(P\right.$ et, $\left.\mathrm{CO}_{2}\right)$ of subject 1 , as well as the variation in $V \mathrm{~T}$ and $f \mathrm{R}$ during $3 \mathrm{~min}$ of maximal ventilatory effort. Results for all subjects are summarized in table 1 . Average $P$ et, $\mathrm{CO}_{2}$ for 10 breaths at control, the first $10 \mathrm{~s}$ of hyperventilation (" 0 " min) and 1.5 and 3 min were (mean \pm SE) $5.1 \pm 0.1 \mathrm{kPa}(38.1 \pm 1.1 \mathrm{mmHg}), 4.9 \pm 0.1 \mathrm{kPa}(36.4 \pm 1.1$ $\mathrm{mmHg}), 5.0 \pm 0.2 \mathrm{kPa}(37.8 \pm 1.6 \mathrm{mmHg})$ and $5.0 \pm 0.2 \mathrm{kPa}$ $(37.6 \pm 1.4 \mathrm{mmHg})(\mathrm{p}=0.53$, ANOVA $)$, respectively. 

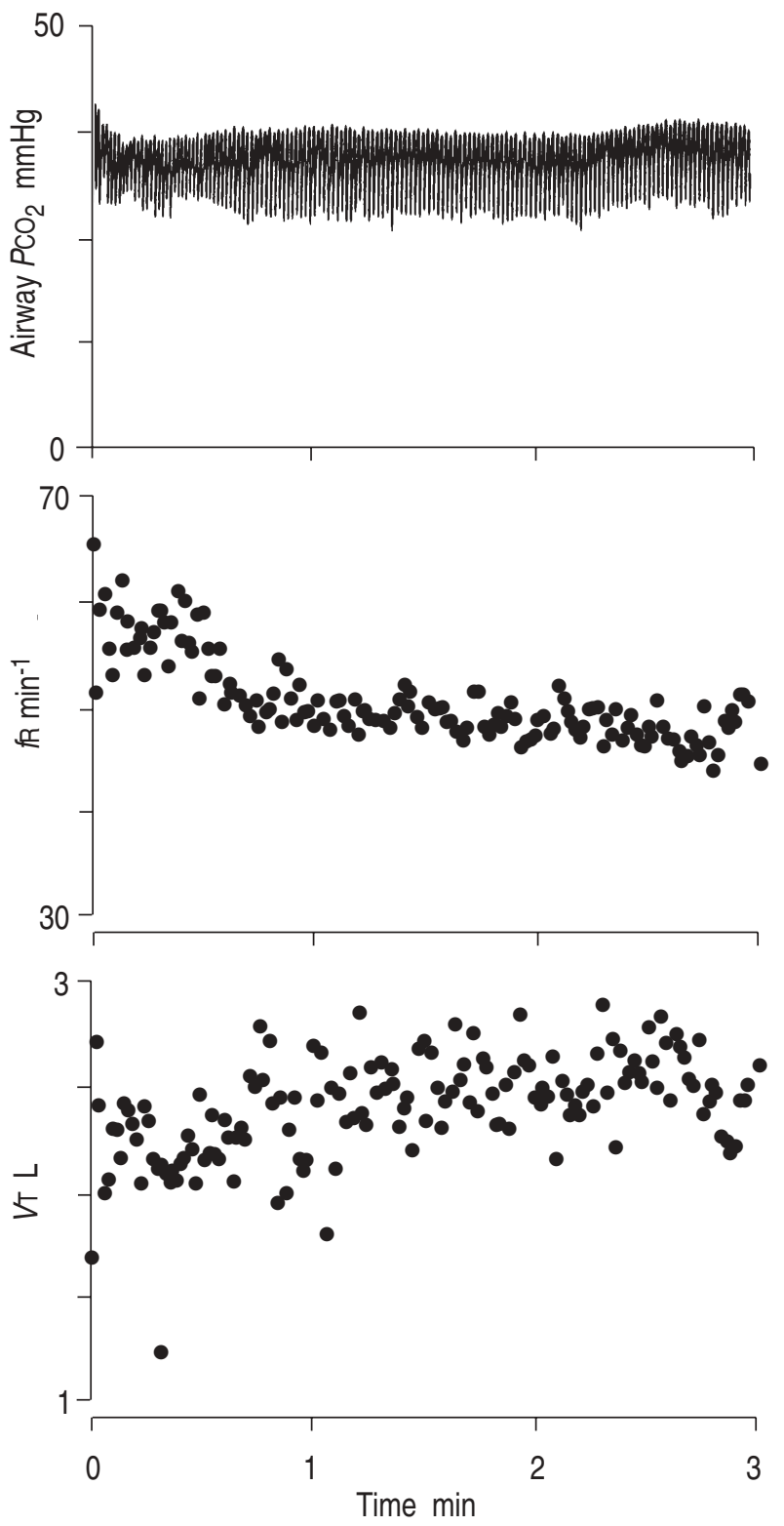

Fig. 2. - Breath-by-breath airway carbon dioxide tension $\left(\mathrm{PCO}_{2}\right)$, respiratory frequency $(f \mathrm{R})$ and tidal volume $(V \mathrm{~T})$ for subject 1 during maximum voluntary ventilation for $3 \mathrm{~min}$. After an initial small decline (due to the delayed appearance of $\mathrm{CO}_{2}$ produced by the increased work of breathing), $\mathrm{PCO}_{2}$ varied $<0.4 \mathrm{kPa}(<3 \mathrm{mmHg})$ from onset despite large variations in $V \mathrm{~T}$ and $f \mathrm{R}$. $(1 \mathrm{mmHg}=0.133 \mathrm{kPa}$. $)$

\section{Dogs}

Figure 3 presents traces of airway $P_{C_{2}}$ and $V \mathrm{~T}$ for dog 5 during changes in $f \mathrm{R}$ or $V \mathrm{~T}$. Figure 4 shows the changes in $P \mathrm{a}, \mathrm{CO}_{2}$ in all dogs during changes in $f \mathrm{R}$ or $V \mathrm{~T}$. The maximum increase in $f \mathrm{R}$ did not affect mean $\mathrm{Pa}_{\mathrm{a}} \mathrm{CO}_{2}(-0.3 \pm 0.2$ $\mathrm{kPa}(-2.2 \pm 1.8 \mathrm{mmHg})$, range 0.1 to $-0.6 \mathrm{kPa}(0.4$ to -4.8 $\mathrm{mmHg}), \mathrm{p}=0.28)$. Increases in $V \mathrm{~T}$ decreased mean $\mathrm{Pa}_{\mathrm{a}} \mathrm{CO}_{2}$ only at a $V \mathrm{~T}$ of $1200 \mathrm{~mL}$ (by $-0.5 \pm 0.3 \mathrm{kPa}(-3.4 \pm 2.3$ $\mathrm{mmHg}$ ), range 0.1 to $-0.7 \mathrm{kPa}(0.4$ to $-5.6 \mathrm{mmHg}), \mathrm{p}<$ $0.05)$.

\section{Discussion}

The circuit maintained $P \mathrm{a}, \mathrm{CO}_{2}$ at control values in humans despite a wide range of ventilatory patterns and up to a
Table 1. - Minute ventilation ( $\left.V^{\prime} E\right)$ and end-tidal carbon dioxide tension $\left(P_{\mathrm{et}}, \mathrm{CO}_{2}\right)$ during maximal ventilatory efforts in human subjects

\begin{tabular}{lcrrr}
\hline & & \multicolumn{3}{c}{ Time min } \\
\cline { 3 - 5 } Subject & Control & 0 & 1.5 & 3 \\
\hline $\boldsymbol{V}^{\prime} \mathbf{E}$ & & & & \\
1 & & 131 & 124 & 118 \\
2 & & 75 & 63 & 56 \\
3 & & 80 & 78 & 68 \\
4 & & 117 & 80 & 76 \\
5 & & 153 & 109 & 93 \\
6 & & 83 & 93 & 79 \\
7 & & 120 & 82 & 84 \\
8 & & 74 & 53 & 57 \\
9 & & 150 & 104 & 90 \\
$\boldsymbol{P e t}_{\text {CO}} \mathbf{C O}_{2}$ & & & & \\
1 & 40.3 & 33.6 & 34.9 & 35.6 \\
2 & 36.6 & 30.9 & 28.1 & 28.0 \\
3 & 42.0 & 42.5 & 43.2 & 42.7 \\
4 & 41.0 & 34.5 & 38.8 & 38.8 \\
5 & 35.6 & 37.3 & 41.9 & 41.2 \\
6 & 41.5 & 39.1 & 39.1 & 38.9 \\
7 & 36.6 & 36.7 & 36.5 & 36.4 \\
8 & 32.8 & 37.6 & 35.6 & 36.3 \\
9 & 36.5 & 35.6 & 42.1 & 40.4 \\
\hline
\end{tabular}

Values represent averages of 10 breaths at control, onset $(0$ $\min ), 1.5$ and $3 \mathrm{~min}$.

30-fold increase in $V^{\prime} \mathrm{E}$, which otherwise should have lowered $\mathrm{PCO}_{2}$ by at least $2.7 \mathrm{kPa}(20 \mathrm{mmHg})$. At constant $\mathrm{CO}_{2}$ production and dead space, these maximal increases in ventilation tested to the limit the ability of the circuit to prevent changes in $\mathrm{PCO}_{2}$. In ventilated dogs, $\mathrm{Pa}_{\mathrm{a}} \mathrm{CO}_{2}$ decreased only at the highest $V$ T. The greater changes in $P a, \mathrm{CO}_{2}$ in the dogs were attributed to: 1) imprecise matching of the $P_{\mathrm{CO}_{2}}$ of the reserve gas to the dog's $\left.P_{\mathrm{v}}, \mathrm{CO}_{2} ; 2\right)$ prolonged duration of the manoeuvre in $\operatorname{dogs}(>15 \mathrm{~min}$ versus 3 min for human subjects); 3) the extent of hyperventilation (see below); and 4) possible effects of mechanical ventilation on systemic and pulmonary blood flow (ventilation-perfusion mismatching, physiological and anatomical dead space) and, therefore, $P \mathrm{a}, \mathrm{CO}_{2}$ and $P_{\mathrm{v}}, \mathrm{CO}_{2}$. Nevertheless, the ranges over which $P$ et, $\mathrm{CO}_{2}$ and $P \mathrm{a}, \mathrm{CO}_{2}$ varied in these studies are similar to those reported in studies with less hyperventilation and utilizing more complex equipment $[2,3,8]$.

Although conventional servocontrolled techniques designed to prevent changes in $\mathrm{PCO}_{2}$ with hyperpnoea are less affected by changes in $\mathrm{CO}_{2}$ production than the present circuit, they have limitations. Small changes in ventilatory pattern can uncouple $P$ et, $\mathrm{CO}_{2}$ and $P \mathrm{a}, \mathrm{CO}_{2}$ [7], resulting in $P$ et, $\mathrm{CO}_{2}$ being an inappropriate variable for controlling $P \mathrm{a}, \mathrm{CO}_{2}$. For example, a smaller $V \mathrm{~T}$ decreases $V^{\prime}$ A (which tends to increase $\left.P \mathrm{a}, \mathrm{CO}_{2}\right)$ but will also decrease $P$ et, $\mathrm{CO}_{2}$, causing a servocontroller to respond with an inappropriate increase in $\mathrm{F}, \mathrm{IO}_{2}$. If, in an attempt to obtain fine control, the gain in a servocontrol system is set too high, the response becomes unstable and may result in oscillation of the controlled variable [4]. Conversely, if the gain is set too low, compensation lags [8]. Overdamping of the signal results in the response never reaching the target. To address these problems, servocontrollers require complex algorithms [9] and expensive equipment. 


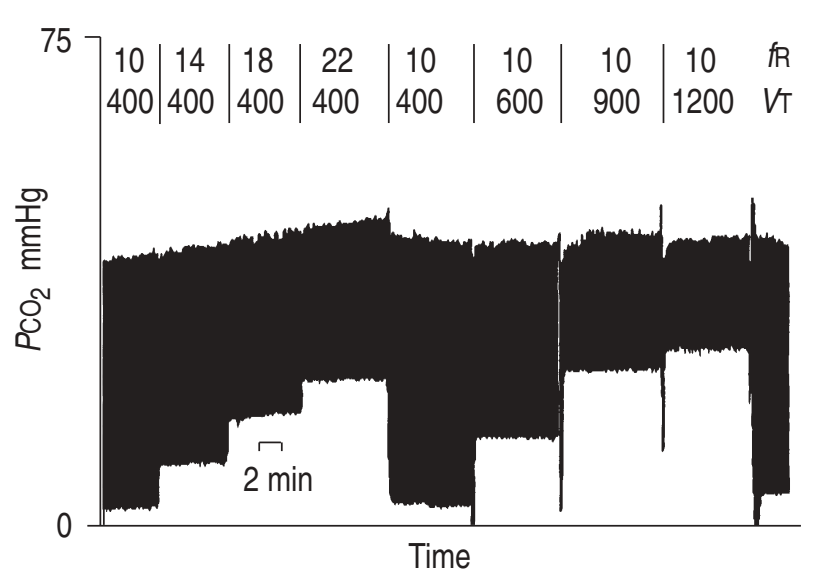

Fig. 3. - Effect of sequential changes in respiratory frequency $(f \mathrm{R})$ and tidal volume $(V \mathrm{~T})$ on airway carbon dioxide tension $\left(\mathrm{PCO}_{2}\right)$ in $\operatorname{dog} 5$. The circuit passively adjusted the inspiratory carbon dioxide fraction $\left(F_{1}, \mathrm{CO}_{2}\right)$ in response to changes in minute ventilation whether caused by changes in $f \mathrm{R}$ or in $V \mathrm{~T}$. Numbers above the graph indicate the level of ventilation at each stage. $(1 \mathrm{mmHg}=0.133 \mathrm{kPa}$. $)$

When $\mathrm{CO}_{2}$ production is constant, this circuit is superior to servocontrolled systems in that it passively compensates for changes in $V^{\prime} \mathrm{E}$ minimizing changes in $V^{\prime} \mathrm{A}$ and pre-empting the need for subsequent compensation. Maintenance of a nearly constant $V^{\prime}$ A occurs even during irregular breathing, including brief periods when $V^{\prime} \mathrm{E}$ is less than the FGF; excess FGF is stored in the fresh gas reservoir and contributes to $V^{\prime} \mathrm{A}$ when ventilation subsequently exceeds FGF.

When $\mathrm{CO}_{2}$ production, and therefore $P \mathrm{v}, \mathrm{CO}_{2}$, increases (e.g. with increased work of breathing or exercise), this method requires modification because FGF, if fixed, will no longer clear enough $\mathrm{CO}_{2}$ to maintain normocapnia. To increase $V^{\prime} \mathrm{A}$, one must increase FGF or decrease the $\mathrm{PCO}_{2}$ of the reserve gas below the $P_{\mathrm{v}, \mathrm{CO}_{2}}$, (Equation 2). Compensating for increased $\mathrm{CO}_{2}$ production by increasing FGF would have required constant adjustment of FGF in hyperpnoeic subjects with variable $V^{\prime} \mathrm{E}$. Therefore, it was decided to decrease the $\mathrm{PCO}_{2}$ of the reserve gas. By trial and error, it was found that $5.5 \% \mathrm{CO}_{2}$ in the reserve gas (instead of $6.5 \%$ corresponding to a $P \mathrm{v}, \mathrm{CO}_{2}$ of $6.1 \mathrm{kPa}(46$ $\mathrm{mmHg}$ ) established a suitable gradient of $\mathrm{CO}_{2}$ partial pressure to match closely $\mathrm{CO}_{2}$ elimination to increases in $\mathrm{CO}_{2}$ production resulting from increased work of breathing at higher $V^{\prime} \mathrm{E}$.

The circuit presented here bears a superficial resemblance to the Mapleson D anaesthetic circuit, which minimizes the effect of changes in total ventilation on $V^{\prime}$ A. However, with that circuit, $V^{\prime} \mathrm{A}$ remains less than FGF at all levels of ventilation but asymptotically approaches FGF at high ventilation [10]. In contrast, the present circuit limits the $V^{\prime}$ A to FGF at any $V^{\prime}$ E greater than FGF.

In summary, we describe a simple circuit that dissociates alveolar ventilation from minute ventilation. It passively minimizes increases in alveolar ventilation that would normally accompany hyperpnoea at constant or, by adjusting the carbon dioxide tension of the reserve gas, increased carbon dioxide production. The circuit may provide a simple and inexpensive alternative to servocontrolled systems for research and have therapeutic applications.
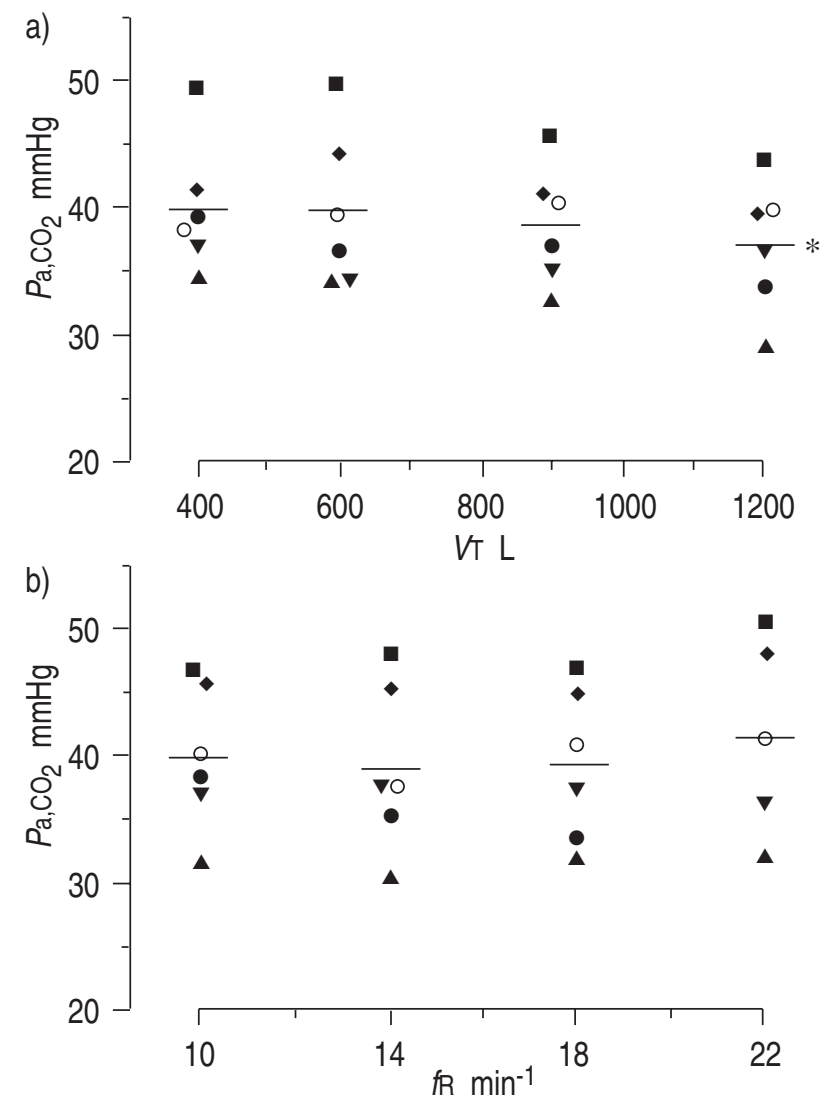

Fig. 4. - Arterial carbon dioxide tension $\left(P \mathrm{a}, \mathrm{CO}_{2}\right)$ resulting from: a) step changes in tidal volume $(V \mathrm{~T})$ at constant respiratory frequency $(f \mathrm{R})$; and b) changes in $f R$ at constant $V$ T. *: $\mathrm{p}<0.05$, significantly different from control. Each symbol represents an individual dog and bar is the mean of the dogs. $(1 \mathrm{mmHg}=0.133 \mathrm{kPa}$. $)$

\section{References}

1. Belman MJ, Mittman C. Ventilatory muscle training improves exercise capacity in chronic obstructive pulmonary disease patients. Am Rev Respir Dis 1989; 121: 273-280.

2. Bradley ME, Leith DE. Ventilatory muscle training and the oxygen cost of sustained hyperpnea. J Appl Physiol 1978; 45: 885-892.

3. McKerrow $\mathrm{CB}$, Otis AB. Oxygen cost of hyperventilation. J Appl Physiol 1956; 9: 275-379.

4. Smith DM, Mercer RR, Eldridge FL. Servo control of end-tidal $\mathrm{CO}_{2}$ in paralyzed animals. J Appl Physiol 1978; 45: 133-136.

5. Somers VK, Mark AL, Zavala DC, Abboud FM. Influence of ventilation and hypocapnia on sympathetic nerve responses to hypoxia in normal humans. J Appl Physiol 1989; 67: 2095-2100.

6. Sorkness R, Vidruk E. Reflex effects of isocapnic changes in ventilation on tracheal tone in awake dogs. Respir Physiol 1987; 69: 161-172.

7. Tenney SM, Reese RE. The ability to sustain great breathing efforts. Respir Physiol 1982; 52: 1353-1357.

8. Robbins PA, Swanson GD, Howson MG. A prediction-correction scheme for forcing alveolar gases along certain time courses. J Appl Physiol 1982; 52: 1353-1357.

9. Ward DS, Michels DB, Swanson GD, Belville JW. Automatic control of end-expiratory carbon dioxide. Proc Rocky Mountain Bioeng Symp 1974; 11: 183-186.

10. Jonsson LO. Predictable $\mathrm{PaCO}_{2}$ with two different flow settings using the Mapleson D system. Acta Anaesthesiol Scand 1990; 34: 237-240. 